\title{
Dynamics of Bioactive Luteinizing Hormone- Human Chorionic Gonadotropin during the First 7 Days of Life ${ }^{1}$
}

\author{
MARCO DANON, OFELIA VELEZ, TEOFILA OSTREA, JOHN D. CRAWFORD, AND
}

INESE Z. BEITINS

\begin{abstract}
Department of Pediatrics, Facultad de Medicina Universidad del Valle, Cali, Colombia; Endocrine Metabolic Unit, Children's Service, Massachusetts General Hospital; Department of Pediatrics, Harvard Medical School, Boston, Massachusetts 02114; and Department of Pediatrics, C. S. Mott Children's Hospital, University of Michigan, Ann Arbor, Michigan 48109
\end{abstract}

\begin{abstract}
Serum luteinizing hormone-human chorionic gonadotropin bioactivity (B-LH) was measured daily in seven male and four female full-term newborns during the first 7 days of life. The B-LH levels were elevated in both sexes during the 1st day of life; subsequently, values decreased in both sexes. In males, they reached a nadir on the 4th day of life. A gradual secondary rise was then observed with B-LH levels on the 7th day significantly higher than on day $4(p<0.025)$. By contrast, the B-LH levels in the females continued a gradual decline to levels significantly lower on day 7 as compared to day 4 ( $p<$ 0.05). To determine whether pulsatile B-LH secretion occurs in newborns, serum concentrations were measured every $\mathbf{2 0} \mathrm{min}$ for $\mathbf{2} \mathrm{h}$ in eight male and seven female fullterm neonates on the 7th day of life. Pulsatile secretion of B-LH was detected in six males and six females. This study demonstrates that pulsatility of gonadotropin secretion is characteristic of neonates as early as 7 days of life and that there is a dichotomy between the levels of B-LH in males and females; levels in females decline progressively from day 1 through 7 , whereas in males, a nadir is reached on day 4 with a secondary rise developing thereafter. This male sex-specific rise is presumably the drive responsible for the characteristic postnatal increase in testosterone which peaks at 1 to 2 months of age. (Pediatr Res 23: 530-533, 1988)
\end{abstract}

\section{Abbreviations}

LH, luteinizing hormone

hCG, human chorionic gonadotropin

B-LH, bioactive luteinizing hormone

RICT assay, rat interstitial cell testosterone assay

2nd-IRP, second international reference preparation

hMG, human menopausal gonadotropin

FSH, follicle-stimulating hormone

LHRH, luteinizing hormone-releasing hormone

Newborn male infants exhibit high serum testosterone concentrations on the 1st day of life (1). This is followed by a decline

Received September 22, 1987; accepted January 20, 1988.

Reprint requests Marco Danon, M.D., Children's Service, Massachusetts General Hospital, Boston, MA 02114.

Supported by Grant HD 18515 to I.Z.B. from the National Institutes of Health

1 Presented at the Annual Meeting of the Society of Pediatric Research, Washington D.C., May 1982 and published in abstract form (Pediatr Res 16:137A, 1982). so that by the end of the 1st wk the levels have diminished to a nadir, at which they are comparable to the levels characteristic of normal childhood. A second and longer sustained rise of plasma testosterone commences in the $2 \mathrm{nd}$ wk of life. Testosterone concentrations rise progressively to plateau during the 2 nd month of life at levels that are not seen again until puberty (2, $3)$. This biphasic course of plasma testosterone concentration presumably relates to changes in testicular secretion and has been correlated with transient elevations in plasma LH concentrations as measured by immunoassay (4).

The present study was undertaken to describe the changes in plasma gonadotropins of the LH-hCG class as measured by bioassay during the first 7 days of life. It was also designed to show whether newborns display pulsatility of gonadotropin secretion of the type seen in normal puberty (5). Finally, it afforded an opportunity to contrast the pattern of bioactive gonadotropins in the male with that in female neonates.

\section{MATERIALS AND METHODS}

Clinical studies. Studies were carried out in two groups of neonates according to protocols approved by the Human Studies Committee of the Universidad del Valle. The first group consisted of seven male and four female newborns. All of the infants were products of normal pregnancies, spontaneous labor, and vaginal deliveries. They were of appropriate weights for gestational age and judged healthy on the basis of behavior and detailed physical examination. Mean birth weights, Apgar scores, and gestational ages were not significantly different between males and females (Table 1). All babies were breast-fed. The mothers were informed of the nature and purpose of the study and gave consent for withdrawal from their infants of $3 \mathrm{ml}$ of venous blood daily for the first 7 days of life. Sera were separated by centrifugation and stored at $-20^{\circ} \mathrm{C}$ until assay.

The second group consisted of eight male and seven female healthy, full-term infants who were studied on the 7th day of life. The ages of the mothers as well as the infants' gestational ages, birth weights, and Apgar scores are shown in Table 2. Data are comparable for both sexes. All pregnancies had been uneventful, all infants were delivered vaginally after spontaneous labors, and all were breast-fed. After obtaining their parents' consent to carry through the specific protocol, $2 \mathrm{ml}$ of venous blood was withdrawn every $20 \mathrm{~min}$ for a period of $2 \mathrm{~h}$ from peripheral veins of eight male and seven female 1 -wk-old infants. The time of blood sampling was between 1000 and $1200 \mathrm{~h}$. Samples were allowed to clot and were then centrifuged and the sera separated and stored at $-20^{\circ} \mathrm{C}$ until assay.

Bioassay. The B-LH was determined by the RICT assay as 
Table 1. Perinatal data in neonates studied from day 1 to $7 *$

\begin{tabular}{|c|c|c|c|}
\hline & & Males $(n=7)$ & Females $(n=4)$ \\
\hline Maternal age & $\begin{array}{l}\text { Mean } \\
\text { Range }\end{array}$ & $\begin{array}{l}22 \mathrm{yr} \\
(19-28)\end{array}$ & $\begin{array}{l}22 \mathrm{yr} \\
(20-26)\end{array}$ \\
\hline Gestational age & $\begin{array}{l}\text { Mean } \\
\text { Range }\end{array}$ & $\begin{array}{l}40 w k \\
(39-41)\end{array}$ & $\begin{array}{l}40 w k \\
(38-41)\end{array}$ \\
\hline Birth wt & $\begin{array}{l}\text { Mean } \\
\text { Range }\end{array}$ & $\begin{array}{l}3290 \mathrm{~g} \\
(3000-3600)\end{array}$ & $\begin{array}{l}3130 \mathrm{~g} \\
(3000-3400)\end{array}$ \\
\hline
\end{tabular}

* All pregnancies were uneventful and the infants' Apgar scores were 9 or 10 at birth.

Table 2. Perinatal data of infants studied on day 7 of life*

\begin{tabular}{llcc}
\hline & & Males $(n=8)$ & Females $(n=7)$ \\
\hline Maternal age & Mean & $24 \mathrm{yr}$ & $21 \mathrm{yr}$ \\
& Range & $(20-27)$ & $(19-26)$ \\
\multirow{5}{*}{ Gestational age } & Mean & $40 \mathrm{wk}$ & $39 \mathrm{wk}$ \\
& Range & $(39-41)$ & $(38-40)$ \\
Birth wt & & & \\
& Mean & $3320 \mathrm{~g}$ & $3280 \mathrm{~g}$ \\
& Range & $(3130-3530)$ & $(3100-3520)$ \\
\hline
\end{tabular}

* All pregnancies were uneventful and the infant's Apgar scores were 9 or 10 at birth.

described by Dufau et al. (6). Testis tissue from Sprague-Dawley rats weighing 200 to $250 \mathrm{~g}$ was digested in collagenase, the interstitial cells isolated and incubated with serum samples and standards for luteinizing hormone in triplicate as previously detailed (7). The results were expressed as $\mathrm{mIU} / \mathrm{ml}$ of serum of the 2nd IRP-hMG for the sake of comparison with previously published data from this laboratory. If the CR119 standard was used, then a parallel curve was obtained and at $50 \%$ response, 2 mIU of 2 nd IRP-hMG was equivalent to $40 \mathrm{pg}$ of CR119. The lower limit of detection was $0.25 \mathrm{mIU} /$ assay tube. The intra- and interassay coefficients of variation were 5 and $7 \%$, respectively. All samples from each study were measured within the same assay.

Pulse analysis. A pulsatile episode was defined as a rise in BLH from nadir to peak equal to or greater than $20 \%$ of the nadir value (8). Twenty percent was at least three times greater than the coefficient of variation of our B-LH assay (mean intraassay coefficient of variation was $5 \%$ ). A similar definition has previously been described to estimate LH pulsatile secretion in prepubertal children (9). The statistic coefficient of variation was used as a measure of the amplitude of pulsatility. The mean and SD of the B-LH concentration in the seven samples obtained at 20 -min intervals during $2 \mathrm{~h}$ in each of the 7-day-old infants were computed. The size of the SD relative to its mean, or the coefficient of variation, was used as a means of expressing the extent of fluctuation of B-LH values attributed to pulsatility.

Statistics. The statistical evaluation was performed by means of Student's $t$ test and paired $t$ test.

\section{RESULTS}

B-LH in first 7 days of life. Bioassayble serum hCG-LH (B$\mathrm{LH})$ showed the maximum mean value on the 1st day of life, both in the seven males and the four females $(139.3 \pm 39.8$ and $74.6 \pm 24.1 \mathrm{mIU} / \mathrm{ml}$, respectively) (Fig. 1). In the subsequent days, the B-LH levels decreased progressively. In the males, the lowest values $(13.7 \pm 3.1 \mathrm{mIU} / \mathrm{ml})$ were reached on the 4 th day of life when the mean was significantly lower $(p<0.01)$ than on the 1st day. This nadir was superseded by a gradual rise over the next 3 postnatal days to a mean of $28.7 \pm 10.4 \mathrm{mIU} / \mathrm{ml}$ on the
7 th day of life, significantly higher $(p<0.025)$ than on day 4 . In the four females there was also a rapid decrease in B-LH concentrations after birth; the level on the 4th day of life was $9.4 \pm 1.5$ $\mathrm{mIU} / \mathrm{ml}$, significantly lower $(p<0.05)$ than the mean level on the 1st day. However, in the females, contrary to the males, the B-LH levels continued a gradual decline so that by day 7 of life the B-LH was $4.1 \pm 0.06 \mathrm{mIU} / \mathrm{ml}$, significantly lower $(p<0.05)$ than the mean level observed on day 4 or than the level exhibited by the males on the 7th day of life.

$B-L H$ on 7 th day of life. The patterns of B-LH concentrations obtained from the eight males and seven females during the 2-h study at 1 wk of age are shown in Figure 2. B-LH pulsatile episodes were observed in six of the eight males and in six of the seven females. In one of the males the pulsatile episode was characterized by a rise in B-LH concentration from 2.5 to 19 $\mathrm{mIU} / \mathrm{ml}$. This pulsatile episode resulted in a high coefficient of variation $(69.5 \%)$ relative to the mean for the seven blood samples. The range of values of the coefficient of variation in the males with fluctuations in B-LH meeting the criteria for a pulsatile episode varied from 15.9 to $69.5 \%$. None of the six boys manifesting a pulsatile episode exhibited more than one during the 2-h period of the study.

In the six females exhibiting pulsatility of B-LH concentrations the coefficient of variation ranged from 17.2 to $53.5 \%$. In the female with the largest pulse the B-LH rose from 2.5 to $9.8 \mathrm{mIU} /$ $\mathrm{ml}$. The seven serial measurements of B-LH in this subject yielded the highest coefficient of variation among the females. The coefficients of variation of B-LH in the one female and two males who failed to show pulsatile episodes during the 2-h observation period were $7.7,13.9$, and $12.1 \%$, respectively. As with the males, none of the females exhibited more than one pulsatile episode during the $2 \mathrm{~h}$ of observation.

The mean absolute B-LH increment during pulsatile episodes in the males was $21.6 \mathrm{mIU} / \mathrm{ml}$; whereas the mean was $7.18 \mathrm{mIU} /$ $\mathrm{ml}$ in the 7-day-old females. Expressed in percentage terms, BLH pulses in males were characterized by a mean rise of $340 \%$ over baseline compared with a mean increase of $280 \%$ in girls. Whereas in the terms of the calculations just given, the amplitude of pulses of B-LH appeared more pronounced in the male than in the female infants, an analysis based on the coefficient of variation suggested that the pulses were similar when expressed as perturbations relative to the differing baselines in the two sexes (mean values in males $30.1 \pm 21$ versus $29.4 \pm 16 \%$ in females).

The mean B-LH concentration in the 7-day-old female infants of group 2 was $8.7 \pm 5.2 \mathrm{mIU} / \mathrm{ml}$. This is significantly lower $(p$ $<0.001)$ than that of the eight male infants in whom the mean was $30 \pm 19.5 \mathrm{mIU} / \mathrm{ml}$. This difference confirms the result of the study of trends in B-LH concentration of the males and females of group 1 based on single daily blood samples from the 1 st to the 7th day of life (Fig. 2).

\section{DISCUSSION}

Using one of the most sensitive biological assays for serum LH-hCG (B-LH) $(10,11)$, we have demonstrated dynamic, sexspecific changes in B-LH during the 1st wk of life in the human newborn. In males, these B-LH changes appear to provide an explanation for the changes in plasma testosterone concentration previously described by several authors $(1,4)$. Elevated levels of $\mathrm{B}-\mathrm{LH}$ were observed in the first $24 \mathrm{~h}$ of life and were not different in males and females. Presumably these high B-LH levels in the 1st day represent the sum of chorionic gonadotropin and the LH produced as a result of the infant's pituitary activity. Whether there is a secretory burst of $\mathrm{LH}$ in humans at birth as there is in the rat (12) has not been established. It would seem likely, however, that the level of chorionic gonadotropin at birth is sufficient to provide a substantial stimulus to testicular testosterone production and that the suggestion of Winter et al. (3) is correct that it is the loss of the placenta's clearance function 


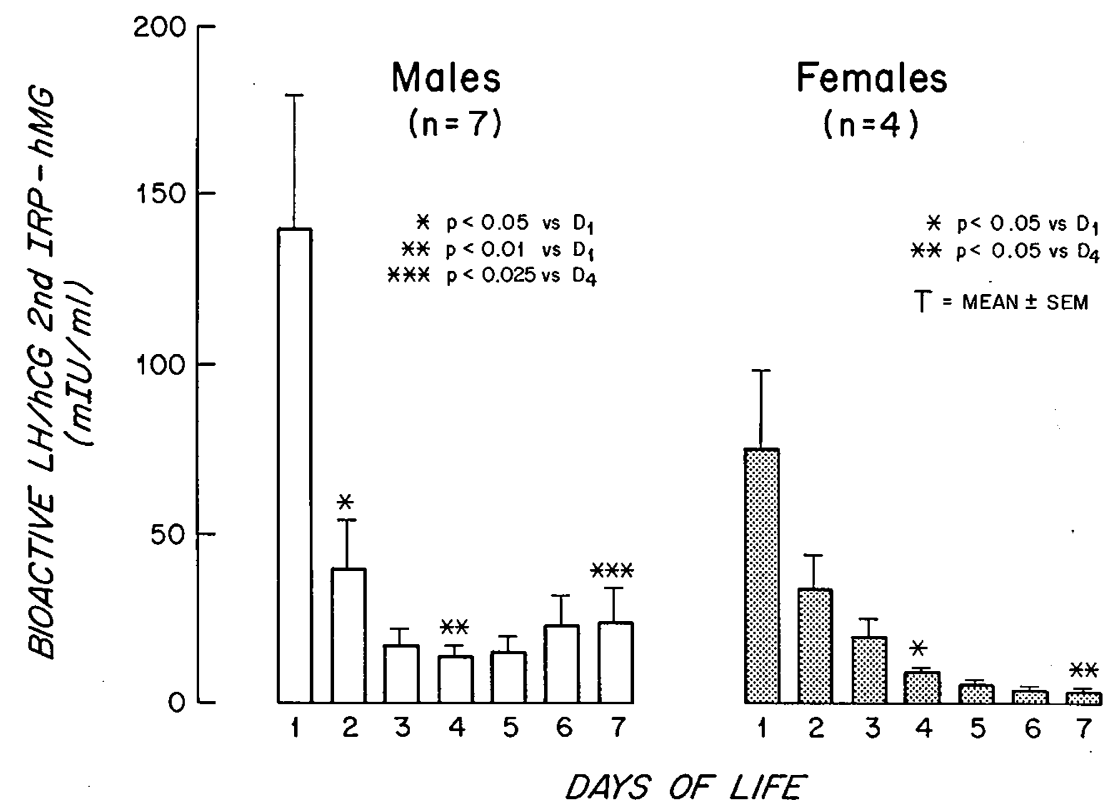

Fig. 1. B-LH/hCG in newborns. Serum concentration of B-LH/hCG during the first 7 days of life. The mean is indicated by the height of columns and the SE by the height of the bar. The asterisks indicate statistically significant differences.

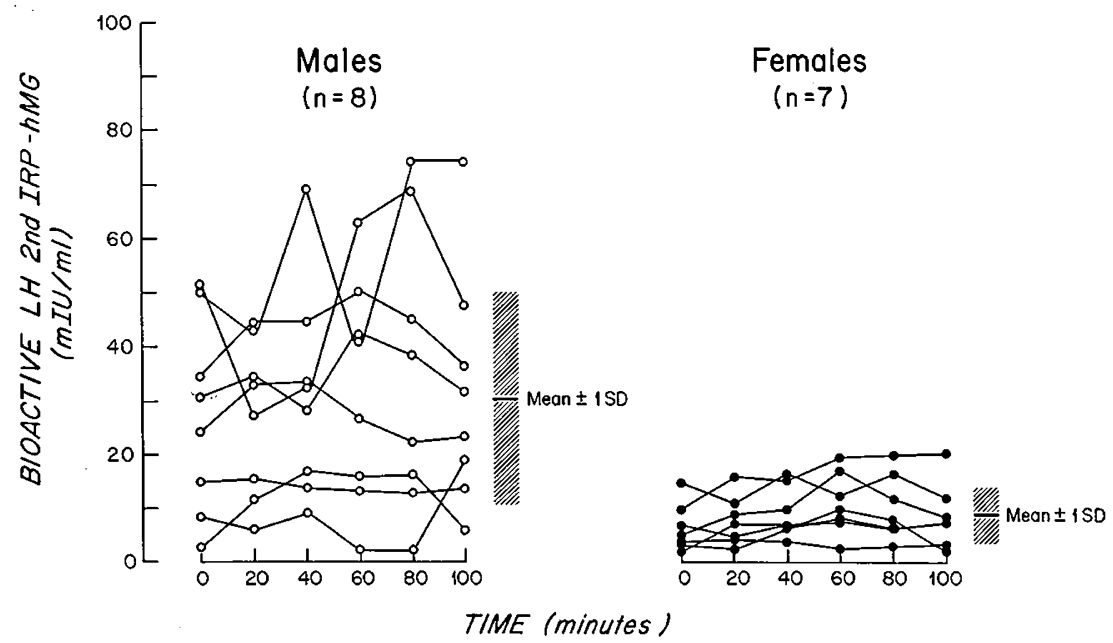

Fig. 2. B-LH in newborns on day 7 of life. Serum B-LH concentrations in serial samples from 7-day-old male and female newborns. Data for individual infants are shown. The hatched bars indicate mean \pm SD for the group.

rather than increased production that accounts for the abrupt rise in plasma testosterone during the male infant's first few hours of life.

The rapid decline of B-LH over the next 3 postnatal days in both boys and girls is compatible with the brief plasma half-life of hCG (13). Previous studies using radioimmunoassay and antibodies sufficiently specific to permit a reasonable degree of discrimination between hCG and LH suggest that the major plasma gonadotropin at birth is hCG and this gonadotropin is no longer detectable after 4 days of age (14).

To our knowledge, this is the first study to demonstrate that the low levels to which B-LH falls by day 4 in both male and female neonates is followed by a subsequent rise of B-LH in males. By day 7 this secondary rise achieved levels significantly higher than the levels on day $4(p<0.025)$. The serum concentrations of B-LH in 7-day-old male neonates were similar to those found by Torresani et al. (15) in five boys with congenital hypothyroidism from 10 to 30 days of life. The elevated B-LH levels persist up to about 8 months of life and then rapidly decline to the low prepubertal levels (15). Similar serum B-LH levels are next achieved in boys with pubertal stages classified as
Tanner IV and V (7). The brisk rise of B-LH in males from the nadir on day 4 probably represents active endogenous B-LH secretion and thus suggests activity of the hypothalamic-hypophyseal axis. This concept is further supported by the fact that newborn males have responded to exogenous LHRH with a pubertal pattern of LH secretion (16).

In the females, in contrast to the males, serum B-LH concentrations also decreased significantly by day $4(p<0.05)$ but then continued to decline reaching significantly lower values on postnatal day 7 than on day $4(p<0.05)$. The reasons for this dichotomy are not known. In previous studies using immunoassays, serum LH in girls was found to be lower than in boys on postnatal day 7 (17) and using in vitro bioassays in older infants ( 2 to 7 months old) B-LH levels were similarly lower in girls than in boys (15). In the female neonate, the hypothalamic-pituitary axis is active but the predominant gonadotropin secreted during the 1st wk of life is FSH rather than LH (14).

On the 7th day of life in both sexes, B-LH appeared to be secreted in a pulsatile manner. The blood samples were withdrawn too infrequently and for too short a time interval to be able to apply pulse analysis programs and determine pulse fre- 
quency or amplitude. However, on the 7 th day of life, especially in the males, B-LH serum patterns resembled those found with immunoassayable $\mathrm{LH}$ in infants 42 to 78 days of age (18). The baseline B-LH serum values were significantly higher than in prepubertal children $(9,19)$ and the B-LH pulses were in fact more easily detectable (19). The biological implications of these findings are uncertain, but it appears that in 1-wk-old males, the high and relatively pulsatile B-LH serum levels could be responsible for the rising testosterone concentrations characteristic of this time in early infancy.

\section{REFERENCES}

1. Forest MG, Cathiard AM 1975 Pattern of testosterone and $\Delta^{4}$-androstenedione in normal newborns: evidence for testicular activity at birth. J Clin Endocrinol Metab 41:977-980

2. Forest MG, Sizonenko PC, Cathiard AM, Bertrand J 1974 Hypophysogonadal function in humans during the first year of life. J Clin Invest 53:819-828

3. Winter JSD, Hughes IA, Reyes FI, Faiman C 1976 Pituitary-gonadal relations in infancy: 2. Patterns of serum gonadal steroid concentrations in man from birth to two years of age. J Clin Endocrinol Metab 42:679-686

4. GendreI D, Chaussain JL, Roger M, Job JC 1980 Simultaneous postnatal rise of plasma $\mathrm{LH}$ and testosterone in male infants. J Pediatr 97:600-602

5. Boyar RM, Rosenfeld RS, Kapen S, Finkelstein JW, Roffwarg HP, Weitzman ED, Hellman L 1974 Human puberty. Simultaneous augmented secretion of luteinizing hormone and testosterone during sleep. J Clin Invest 54:609618

6. Dufau ML, Pock R, Neubauer A, Catt KJ 1976 In vitro bioassay of LH in human serum: the rat interstitial cell testosterone (RICT) assay. J Clin Endocrinol Metab 42:958-969

7. Reiter EO, Beitins IZ, Ostrea T, Gutai JP 1982 Bioassayable luteinizing hormone during childhood and adolescence and in patients with delayed pubertal development. J Clin Endocrinol Metab 54:155-161
8. Reame N, Sauder SE, Kelch RP, Marshall JC 1984 Pulsatile gonadotropin secretion during the human menstrual cycle: evidence for altered frequency of gonadotropin-releasing hormone secretion. J Clin Endocrinol Metab 59:328-337

9. Jakacki RI, Kelch RP, Sauder SE, Lloyd JS, Hopwood NJ, Marshall JC 1982 Pulsatile secretion of luteinizing hormone in children. J Clin Endocrinol Metab 55:453-458

10. Beitins IZ, Dufau ML, O'Loughlin K, Catt KJ, McArthur JW 1977 Analysis of biological and immunological activities in the two pools of LH released during constant infusion of luteinizing-hormone-releasing hormone (LHRH) in men. J Clin Endocrinol Metab 45:605-608

11. Lucky AW, Rich BH, Rosenfield RL, Fang VS, Roche-Bender N 1980 LH bioactivity increases more than immunoreactivity during puberty. $\mathrm{J}$ Pediatr 97:205-213

12. Corbier $\mathrm{P}$, Kerdelhue $\mathrm{B}$, Picon $\mathrm{R}$, Roffi J 1978 Changes in testicular weight and serum gonadotropin and testosterone levels before, during and after birth in the perinatal rat. Endocrinology 103:1985-1991

13. Midgley AR, Jaffe RB 1968 Regulation of human gonadotropins: II. Disappearance of human chorionic gonadotropin following delivery. J Clin Endocrinol Metab 28:1712-1718

14. Winter JSD, Faiman C, Hobson WC, Prasad AV, Reyes FI 1975 Pituitarygonadal relations in infancy. I. Patterns of serum gonadotropin concentrations from birth to four years of age in man and chimpanzee. J Clin Endocrinol Metab 40:545-551

15. Torresani T, Schuster E, Illig R 1983 Bioactivity of plasma luteinizing hormone in infants and young children. Acta Endocrinol 103:326-330

16. Delitala G, Meloni T, Masala A, Alagna S, Devilla L, Corti R 1978 Effect of LRH on gonadotropin secretion in newborn male infants. J Clin Endocrinol Metab 46:689-690

17. Cacciari E Cicognani A, Pirazoli P, Dallacasa $M$, Mazzaracchio Tassoni $P$, Bernardi F, Salardi S, Zappulla F 1976 GH, ACTH, LH and FSH behavior in the first seven days of life. Acta Paediatr Scand 65:337-341

18. Waldhauser F, Weissenbacher G, Frisch H, Pollak A 1981 Pulsatile secretion of gonadotropins in early infancy. Eur J Pediatr 137:71-74

19. Reiter EO, Biggs DE, Veldhuis JD, Beitins IZ 1987 Pulsatile release of bioactive LH in prepubertal girls: discordance with immunoreactive LH pulses. Pediatr Res 21:409-413 